\title{
INFLUÊNCIA DA QUANTIDADE DE ÁGUA NO SUBSTRATO SOBRE A GERMINAÇÃO DE SEMENTES DE PAU-PRETO (Cenostigma tocantinum DUCKE)
}

Noemi Vianna Martins Leão ${ }^{1}$, Marcus Victor Almeida Campos ${ }^{2}$, Sérgio Heitor Sousa Felipe $^{3}$, Elizabeth Santos Cordeiro Shimizu ${ }^{4}$

${ }^{1}$ Pesquisadora do Laboratório de Sementes Florestais, Embrapa Amazônia Oriental, Belém, PA, Brasil. E-mail: noemi.leao@embrapa.br

${ }^{2}$ Mestrando em Ciências Ambientais na Universidade do Estado do Pará, Belém, PA, Brasil.

${ }^{3}$ Doutor em Botânica, Universidade Federal de Viçosa, Viçosa, MG, Brasil.

${ }^{4}$ Analista do Laboratório de Sementes Florestais, Embrapa Amazônia Oriental, Belém, PA, Brasil.

\section{Recebido em: 06/04/2019 - Aprovado em: 10/06/2019 - Publicado em: 30/06/2019} DOI: 10.18677/EnciBio_2019A77

\begin{abstract}
RESUMO
O conhecimento das condições adequadas de água em testes de germinação garante maior segurança no comércio de sementes por meio da padronização das análises para a avaliação de diferentes lotes de sementes. O presente estudo objetivou avaliar a influência da quantidade de água no substrato sobre a germinação de sementes de pau-preto (Cenostigma tocantinum). As sementes de pau-preto foram coletadas em quatro árvores matrizes localizadas na área da Embrapa Amazônia Oriental, Belém, Pará. O delineamento experimental foi inteiramente casualizado (DIC) em esquema fatorial $2 \times 4$ [dois tipos de embalagem (com e sem saco plástico) e quatro níveis de quantidades de água $(2 ; 2,5 ; 3$ e 3,5)], com 4 repetições de 25 sementes por tratamento. Os tratamentos sem saco plástico afetaram drasticamente a porcentagem de germinação, enquanto nos tratamentos com saco, apresentaram as maiores porcentagens nas condições de água equivalentes a 2,0 e 3,0 vezes o peso do substrato (74 e $70 \%$, respectivamente). 0 índice de velocidade e tempo médio de germinação apresentaram os melhores resultados na presença de saco plástico e quantidades de água variando de 2 a 3 vezes o peso do substrato. Os tratamentos sem saco plástico apresentaram elevado número de sementes duras, enquanto a presença de saco plástico evidenciou as maiores médias para porcentagem de plântulas normais. Em conclusão, a quantidade de água igual a 2,5 vezes o peso do papel com a presença de saco é indicada para a condução dos testes de germinação das sementes de pau-preto.
\end{abstract}

PALAVRAS-CHAVE: semente florestal, tecnologia de sementes, umidade do substrato, volume de água. 


\title{
INFLUENCE OF THE AMOUNT OF MOISTURE IN THE SUBSTRATE ON THE GERMINATION OF PAU-PRETO (Cenostigma tocantinum DUCKE) SEEDS
}

\begin{abstract}
The knowledge of the adequate water conditions in germination tests allows greater security in the seed trade through the standardization of the analyses for the evaluation of different seed lots. The objective of this study was to evaluate the influence of the amount of water in the substrate on the germination of black-wood (Cenostigma tocantinum) seeds. Black-wood seeds were collected from four mother trees belonging to the Embrapa Amazônia Oriental area, Belém, Pará. The experimental design was completely randomized (DIC) in factorial $2 \times 4$ [two types of packaging (with and without plastic bag) and four levels of water $(2 ; 2.5 ; 3$ and 3.5$)$ ], with 4 replicates of 25 seeds per treatment. The treatments without plastic bag affected drastically the percentage of germination, while in the bag treatments presented the highest percentages in water conditions equivalent to 2.0 and 3.0 times the substrate weight (74 and $70 \%$, respectively). The speed index and the mean germination time presented the best results in the presence of a plastic bag and water quantities ranging from 2 to 3 times the weight of the substrate. The treatments without plastic bag presented high number of hard seeds, while the presence of plastic bag showed the highest averages for percentage of normal seedlings. In conclusion, the amount of water equal to 2.5 times the weight of the paper with the presence of a bag is indicated for the conduction of germination tests of black-wood seeds.
\end{abstract}

KEYWORDS: forest seed, seed technology, substrate moisture, water volume.

\section{INTRODUÇÃO}

A propagação via sexuada é o principal método de produção de mudas de espécies florestais e o teste de germinação fornece informações sobre a qualidade fisiológica e vigor de sementes de diferentes lotes (BRASIL, 2009; SILVA et al., 2017). Deste modo, é essencial conhecer quais fatores influenciam as análises de germinação para que possam ser controlados e manipulados de forma a otimizar a porcentagem, velocidade e uniformidade de germinação (PEREIRA et al., 2018). A realização de pesquisas para a definição de protocolos de análise de sementes florestais nativas em laboratório fortalece diretamente o setor florestal de espécies nativas, garantindo maior segurança no comércio de sementes (LEÃO et al. 2015; FREITAS et al., 2018).

As variações observadas na germinação de diferentes espécies estão diretamente relacionadas a características físicas, sanitárias e fisiológicas de cada espécie (LEÃO et al., 2018). Contudo, poucos estudos têm abordado o efeito da disponibilidade de água sobre a germinação de sementes florestais. A água promove a reativação do sistema metabólico das sementes por meio de mudanças fisiológicas e bioquímicas capazes de sinalizar para que ocorra a divisão e expansão celular, culminando na retomada do crescimento do embrião e a protrusão da raiz primária (MARCOS-FILHO, 2015).

Nesse sentido, devido elevada biodiversidade encontrada na Amazônia, pesquisar espécies nativas deste Bioma, principalmente as que possuem poucas informações como o pau-preto (Cenostigma tocantinum Ducke), poderão subsidiar informações que possam ser aplicadas na avaliação de lotes de sementes para fins de comercialização dessa espécie. 
O pau-preto é uma espécie com elevado interesse comercial e ecológico devido apresentar características favoráveis para arborização urbana como tronco reto, crescimento rápido, copa frondosa sem a liberação de grande quantidade de folhas e sistema radicular pouco agressivo (GARCIA et al., 2008). Essa essência florestal também pode ser utilizada na construção civil, como caibros, ripas, vigas e pode ser utilizada em obras externas ao alta possuir madeira de alta durabilidade ao ser exposta as condições ambientes (LORENZI, 1998).

Estudos com espécies arbóreas evidenciaram que a quantidade de água no substrato pode influenciar a germinação de espécies florestais, conforme reportado para braúna (Melanoxylon braúna) (FLORES et al., 2013); urucum (Bixa orellana) (SOUSA et al., 2015) e farinha-seca (Albizia niopoides) (OLIVEIRA-SILVA et al., 2017). Diante do exposto, o presente estudo objetivou avaliar a influência da quantidade de água no substrato sobre a germinação de sementes de Cenostigma tocantinum Ducke.

\section{MATERIAL E MÉTODOS}

A pesquisa foi desenvolvida no Laboratório de Sementes Florestais (LASF) da Embrapa Amazônia Oriental, Belém, PA. As sementes de pau-preto foram obtidas de quatro árvores matrizes localizadas na área da Embrapa. Após a colheita das sementes, formou-se um lote de sementes e determinou-se a umidade pelo método de estufa a $105 \pm 3^{\circ} \mathrm{C}$ durante o período de 24 horas, com quatro repetições de $5 \mathrm{~g}$ por cápsula de acordo com as Regras para Análise de Sementes (RAS) (BRASIL, 2009).

Para desinfestação de possíveis patógenos, as sementes foram imersas em solução de hipoclorito de sódio $(\mathrm{NaClO})$ à $2 \%(\mathrm{~m} / \mathrm{v})$ por três minutos, seguido da lavagem em água destilada por três vezes. Posteriormente, as sementes foram acondicionadas em papel toalha para retirada do excesso de água antes do teste de germinação.

O experimento de germinação foi realizado em substrato de papel do tipo Germitest, contendo quatro folhas em cada rolo, sendo umedecidos com quantidades de água equivalentes a 2,0; 2,5; 3,0 e 3,5 vezes o peso do papel. Em seguida, as sementes foram dispostas nos papéis de acordo com as RAS (BRASIL, 2009). Os papéis foram embalados em duas condições diferentes, sem saco e com saco plástico envolvendo os mesmos e, posteriormente, foram dispostos horizontalmente em germinador (Nova Técnica; NT 718) com temperatura de $25^{\circ} \mathrm{C}$ e fotoperíodo de 12 horas.

As avalições foram realizadas até ao sétimo dia, momento de estabilização da germinação. Determinou-se a porcentagem de germinação (G; equação 1 ), o tempo médio (TMG; equação 2) e índice de velocidade de germinação (IVG; equação 3) (SANTANA;RANAL, 2004):

$$
G=\left(\sum_{G} / \sum s\right)^{*} 100
$$

(Equação 1)

Em que:

$\mathrm{G}=$ Porcentagem de germinação. 
$\sum G=0$ somatório de sementes germinadas até o momento da estabilização.

$\Sigma_{s}=0$ somatório da amostra de sementes.

$T M G=\left(N_{1} T_{1}+N_{2} T_{2}+\ldots+N_{n} T_{n}\right) /\left(N_{1}+N_{2}+\ldots+N_{n}\right) \quad$ (Equação 2)

Em que:

TMG = Tempo Médio de emergência.

$G_{1}, G_{2}, G_{n}=0$ número de sementes germinadas nos tempos $T_{1}, T_{2}$ e $T_{n}$, respectivamente.

$I V G=\left(E_{1} / N_{1}\right)+\left(E_{2}+N_{2}\right)+\ldots+\left(E_{n}+N_{n}\right)$

(Equação 3)

Em que:

IVG = Índice de Velocidade de Germinação.

$G_{1}, G_{2}$ e em = o número de sementes germinadas na primeira, segunda e última contagem.

$\mathrm{N}_{1}, \mathrm{~N}_{2}, \mathrm{~N}_{\mathrm{n}}=\mathrm{O}$ número de dias decorridos da semeadura na primeira, segunda e última contagem.

Ao final do experimento foi contabilizada a porcentagem de sementes duras, sementes mortas, plântulas normais, anormais e contaminadas. Consideraram-se sementes duras, as sementes que não germinaram e mantiveram-se integras; as sementes mortas foram as que absorveram água, mas não germinaram e desintegraram; plântulas normais, as que não apresentaram danos na radícula e no hipocótilo, sendo possível diferenciar a região de transição entre os mesmos; plântulas anormais as que exibiram raiz e hipocótilo reduzido $(\leq 1 \mathrm{~cm})$ e presença de lesões nessas estruturas; e plântulas anormais contaminadas, as que apresentaram sinais de fitopatógenos (fungos e/ou bactérias).

O delineamento experimental foi inteiramente casualizado (DIC) em esquema fatorial $2 \times 4$ (dois tipos de embalagem e quatro níveis de quantidades de água), sendo cada tratamento com 4 repetições de 25 sementes. A porcentagem de germinação foi transformada em $V_{(x / 100)}$ para normalização de sua distribuição. Posteriormente, todas as variáveis foram submetidas à ANOVA, e, quando ocorreu significância $(p<0,05)$, aplicou-se a análise de regressão (porcentagem de germinação, tempo médio e índice de velocidade de germinação) e o teste de Tukey a $5 \%$ de probabilidade (porcentagem de plântulas normais, anormais, anormais contaminadas, sementes duras e mortas).

\section{RESULTADOS E DISCUSSÃO}

As sementes apresentaram grau de umidade igual a 5,94\%. A utilização de saco plástico influenciou significativamente nos resultados de porcentagem de germinação $(p<0,05)$ (Tabela 1$)$. Os tratamentos sem saco plástico afetaram drasticamente a porcentagem de germinação, havendo baixa porcentagem, mesmo na condição de maior disponibilidade de água (3,5 vezes o peso do substrato) que 
apresentou média igual a $15 \%$. Por outro lado, nos tratamentos com saco, observaram-se as maiores porcentagens nas condições de água equivalentes a 2,0 e 3,0 vezes o peso do substrato, com médias iguais a 74 e $70 \%$, respectivamente (Figura 1).

TABELA 1- Resumo da análise de variância da porcentagem de germinação de sementes de pau-preto (C. tocantinum) sob diferentes quantidades de água no substrato $(Q)$ e condições de embalagem plásticas (EP).

\begin{tabular}{cccccc}
\hline Fonte & GL & Soma dos quadrados & Média dos quadrados & $F$ & $\operatorname{Pr}>F$ \\
\hline EP & 1 & 29282,00 & 29282,00 & 309,17 & $0,00^{*}$ \\
Q & 3 & 378,00 & 126,00 & 1,33 & $0,29^{\text {ns }}$ \\
EPxQ & 3 & 610,00 & 203,00 & 2,15 & $0,12^{\text {ns }}$ \\
\hline Erro & 24 & 2272,00 & 94,00 & & \\
Total corrigido & 31 & 32542,00 & & & \\
\hline *significativo para $p<0,05 \mathrm{e}^{\text {ns }}-$ não significativo.
\end{tabular}

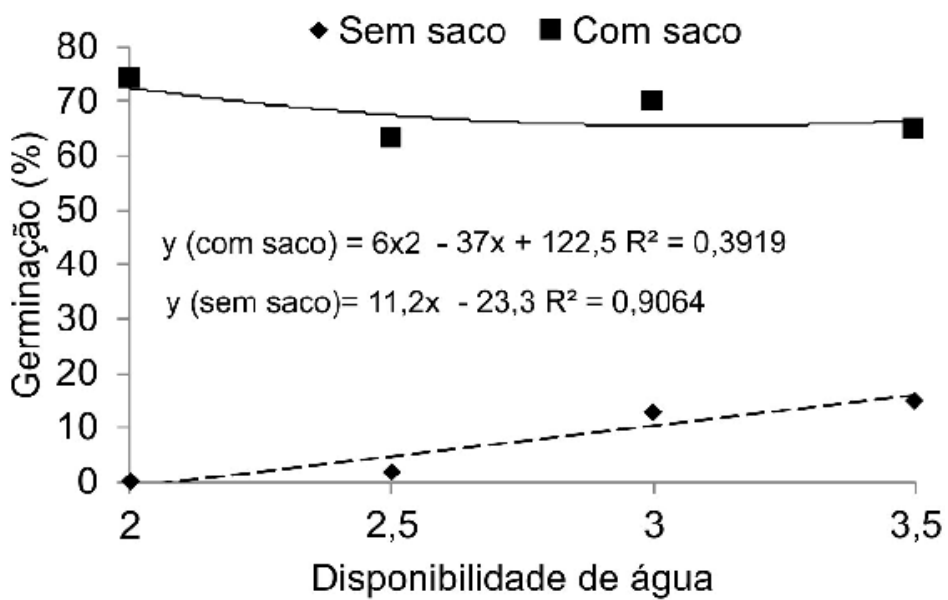

FIGURA 1- Germinação de sementes de pau-preto (C. tocantinum) sob diferentes quantidades de água no substrato e condições de embalagem plásticas.

A utilização de saco plástico envolvendo o rolo de papel toalha não influenciou o poder germinativo de sementes de Arachis hypogaea (TANAKA et al., 1991), diferindo dos resultados desta pesquisa. Em contraste, espécies como Piptadenia moniliformis (AZERÊDO et al., 2016) e Anadenanthera colubrina (DUARTE et al., 2018) a germinação foi comprometida em condições de baixo potencial hídrico, corroborando com os resultados deste estudo. Possivelmente, a ausência de saco plástico para embalar o rolo de papel facilitou evaporação da água para o ambiente externo, desidratando e comprometendo a máxima germinação das sementes de pau-preto, uma vez que tanto o excesso, quanto a deficiência de água são prejudiciais à germinação de sementes (OLIVEIRA-SILVA et al., 2017). Em situações de restrição hídrica a germinação é reduzida drasticamente (SANTOS et al., 2019).

$\mathrm{Na}$ literatura existem estudos que evidenciaram diferentes respostas da germinação de espécies florestais em relação aos diferentes níveis de água no 
substrato. Em Albizia niopoides, os melhores resultados de germinação foram em volumes de água menores, 1 a 2 vezes o peso do substrato (OLIVEIRA-SILVA et al., 2017), enquanto em Parkia plathycenphala as melhores respostas foram nos maiores volumes de água, sendo 2,0; 2,5; 3,0 e 3,5 vezes o peso do papel (GONÇALVES et al., 2015). Essas diferenças entre essas espécies e entre o paupreto revelam que há necessidade de mais pesquisas para outras essências florestais, pois o requerimento de volume de água para a germinação pode ser intrínseco de cada espécie.

De acordo com a Tabela 2 e 3, houve interação significativa entre os dois fatores avaliados (saco plástico e quantidade de água no substrato) para o IVG (Tabela 2) e TMG (Tabela 3). Os tratamentos com ausência de saco plástico mostraram baixo IVG nas condições de 2; 2,5 e 3 vezes o peso do substrato, seguido de aumento somente em 3,5 vezes o peso. Nos tratamentos com presença de saco plástico ocorreu oposto, inicialmente houve aumento do IVG, mas depois decresceu na condição de maior disponibilidade de água (3,5 vezes) (Figura 2).

TABELA 2- Resumo da análise de variância do IVG de sementes de pau-preto ( $C$. tocantinum) sob diferentes quantidades de água no substrato $(Q)$ e condições de embalagem plásticas (EP).

\begin{tabular}{cccccc}
\hline Fonte & GL & Soma dos quadrados & Média dos quadrados & $F$ & $\operatorname{Pr}>F$ \\
\hline EP & 1 & 308,95 & 308,95 & 305,04 & $0,00^{*}$ \\
Q & 3 & 34,12 & 11,37 & 11,23 & $0,00^{*}$ \\
EPxQ & 3 & 160,98 & 53,66 & 52,98 & $0,00^{*}$ \\
\hline Erro & 24 & 24,30 & 1,01 & & \\
Total corrigido & 31 & 528,35 & & & \\
\hline
\end{tabular}

TABELA 3- Resumo da análise de variância do tempo médio de germinação de sementes de pau-preto (C. tocantinum) sob diferentes quantidades de água no substrato (Q) e condições de embalagem plásticas (EP).

\begin{tabular}{cccccc} 
Fonte & GL & Soma dos quadrados & Média dos quadrados & $F$ & $\operatorname{Pr}>F$ \\
\hline EP & 1 & 23,10 & 23,10 & 124,57 & $0,00^{*}$ \\
Q & 3 & 6,48 & 2,16 & 11,66 & $0,00^{*}$ \\
EPxQ & 3 & 10,22 & 3,41 & 18,36 & $0,00^{*}$ \\
\hline Erro & 24 & 4,45 & 0,19 & & \\
Total corrigido & 31 & 44,26 & & & \\
* significativo para $p<0,05 \mathrm{e}^{\mathrm{ns}}-$ não significativo.
\end{tabular}




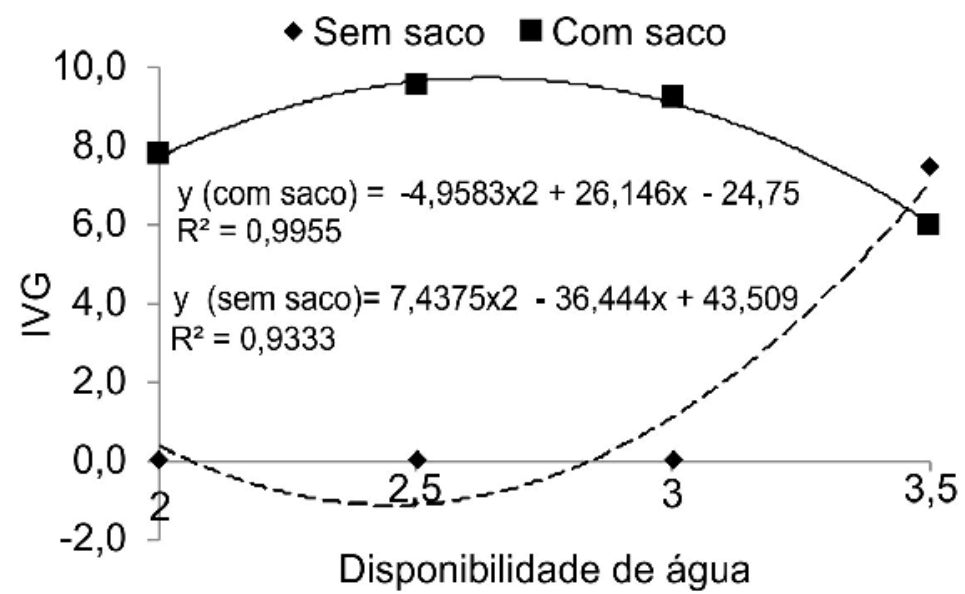

FIGURA 2- Índice de velocidade de germinação (IVG) de sementes de pau-preto ( $C$. tocantinum) sob diferentes quantidades de água no substrato e condições de embalagem plásticas.

Para o TMG, os tratamentos com ausência de saco plástico evidenciaram uma relação dose-dependente, quanto maior foi a disponibilidade de água, maior o TMG. Entretanto, isso não foi observado nos tratamentos com presença de saco plástico, na qual exibiu padrão de resposta similar ao IVG, havendo decréscimo do TMG na condição de maior disponibilidade de água (3,5 vezes) (Figura 3).

TABELA 3- Resumo da análise de variância do tempo médio de germinação de sementes de pau-preto (C. tocantinum) sob diferentes quantidades de água no substrato $(Q)$ e condições de embalagem plásticas (EP).

\begin{tabular}{cccccc}
\hline Fonte & GL & Soma dos quadrados & Média dos quadrados & $F$ & $\operatorname{Pr}>F$ \\
\hline EP & 1 & 23,10 & 23,10 & 124,57 & $0,00^{*}$ \\
Q & 3 & 6,48 & 2,16 & 11,66 & $0,00^{*}$ \\
EPxQ & 3 & 10,22 & 3,41 & 18,36 & $0,00^{*}$ \\
\hline Erro & 24 & 4,45 & 0,19 & & \\
Total corrigido & 31 & 44,26 & & & \\
\hline${ }^{*}$ significtivo
\end{tabular}

${ }^{*}$ significativo para $p<0,05 \mathrm{e}^{\mathrm{ns}}-$ não significativo.

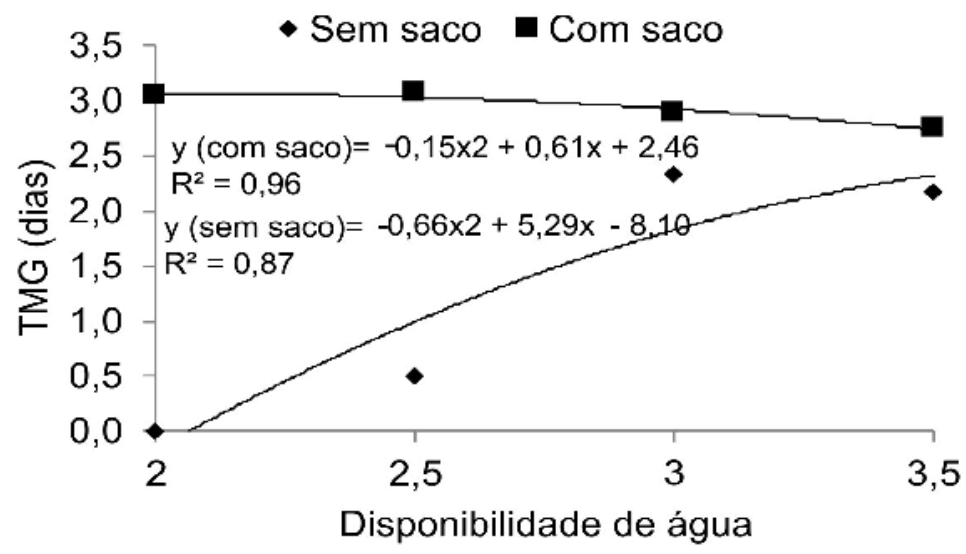

FIGURA 1- Tempo médio de germinação (TMG) de sementes de pau-preto ( $C$. tocantinum) sob diferentes quantidades de água no substrato e condições de embalagem plásticas. 
Para espécies como Hylocereus undatus (OLIVEIRA JUNIOR et al., 2015), Cucumis melo (AMARO et al., 2014) e Mimosa bimucronata (MELO et al., 2018) as sementes apresentaram maior IVG nos tratamentos com maiores volumes de água, diferindo dos resultados obtidos no presente estudo na qual a disponibilidade de 3,5 vezes o peso do substrato não foi favorável para a germinação, IVG e TMG de paupreto. $\mathrm{O}$ excesso de umidade no substrato pode impedir a penetração de oxigênio e afetar negativamente a germinação, além de propiciar maior incidência de fitopatógenos, levando à redução no vigor (MELO et al., 2005).

Os parâmetros de porcentagem de plântulas normais, anormais, anormais contaminadas, sementes duras e mortas de pau-preto estão apresentados na Tabela 4. As duas condições de embalagem plásticas (com e sem plástico) diferiram significativamente para todos os parâmetros analisados $(p<0,05)$. Os tratamentos com saco plástico apresentaram as maiores médias para todas as variáveis, exceto para a porcentagem de sementes duras.

Os tratamentos sem saco plástico não apresentaram plântulas normais, o que pode estar relacionado diretamente à baixa porcentagem de germinação. Enquanto nos tratamentos com saco plástico, observou-se elevada porcentagem nas condições de disponibilidade de água iguais a 2; 2,5 e 3 vezes o peso do substrato (87, 90 e $82 \%$ de plântulas normais, respectivamente), não diferindo entre si, mas todos diferiram para o tratamento com 3,5 vezes o peso do substrato $(64 \%$ de plântulas normais) (Tabela 4).

TABELA 4- Porcentagem de plântulas normais, anormais, anormais contaminadas, sementes duras e mortas de pau-preto ( $C$. tocantinum) sob diferentes quantidades de água no substrato e condições de embalagem plásticas.

\begin{tabular}{|c|c|c|c|c|c|c|c|c|}
\hline \multirow{2}{*}{ Variáveis } & \multirow[t]{2}{*}{ Quantidade de água (Q) } & \multicolumn{4}{|c|}{$\begin{array}{l}\text { Embalagem } \\
\text { Plástica (EP) }\end{array}$} & \multicolumn{3}{|c|}{ Teste F } \\
\hline & & $\mathrm{Se}$ & & & om & $Q$ & EP & QxEP \\
\hline \multirow{4}{*}{$\begin{array}{l}\text { Plântulas } \\
\text { Normais } \\
(\%)\end{array}$} & 2 & 0 & $A b$ & 87 & $\mathrm{Aa}$ & & & \\
\hline & 2,5 & 0 & $A b$ & 90 & $\mathrm{Aa}$ & $1.82^{\text {ns }}$ & $125.92^{*}$ & $1.83^{\text {ns }}$ \\
\hline & 3 & 0 & $A b$ & 82 & $\mathrm{Aa}$ & & & \\
\hline & 3,5 & 0 & $A b$ & 64 & $\mathrm{Ba}$ & & & \\
\hline \multirow{4}{*}{$\begin{array}{l}\text { Plântulas } \\
\text { anormais } \\
\text { (\%) }\end{array}$} & 2 & 0 & $\mathrm{Bb}$ & 8 & $\mathrm{Aa}$ & & & \\
\hline & 2,5 & 0 & $\mathrm{Bb}$ & 3 & $\mathrm{Aa}$ & $1.57^{\text {ns }}$ & $75.05^{*}$ & $1.57^{\mathrm{ns}}$ \\
\hline & 3 & 0 & $\mathrm{Bb}$ & 7 & $\mathrm{Aa}$ & & & \\
\hline & 3,5 & 77 & $\mathrm{Ab}$ & 12 & $\mathrm{Aa}$ & & & \\
\hline \multirow{4}{*}{$\begin{array}{c}\text { Plântulas } \\
\text { Anormais } \\
\text { contaminadas } \\
(\%)\end{array}$} & 2 & 0 & $A b$ & 1 & $\mathrm{Ba}$ & & & \\
\hline & 2,5 & 0 & $A b$ & 2 & $\mathrm{ABa}$ & $2.18^{\text {ns }}$ & $12.33^{*}$ & $2.18^{\text {ns }}$ \\
\hline & 3 & 0 & $A b$ & 3 & $\mathrm{ABa}$ & & & \\
\hline & 3,5 & 0 & $\mathrm{Ab}$ & 6 & $\mathrm{Aa}$ & & & \\
\hline \multirow{4}{*}{$\begin{array}{c}\text { Sementes } \\
\text { Duras } \\
(\%)\end{array}$} & 2 & 99 & $A b$ & 0 & $\mathrm{Aa}$ & & & \\
\hline & 2,5 & 100 & $A b$ & 0 & $\mathrm{Aa}$ & $8.81^{*}$ & $3459.85^{\star}$ & $5.76^{*}$ \\
\hline & 3 & 100 & $A b$ & 0 & $\mathrm{Aa}$ & & & \\
\hline & 3,5 & 23 & $\mathrm{Bb}$ & 0 & $\mathrm{Aa}$ & & & \\
\hline
\end{tabular}




\begin{tabular}{ccccccccc}
\hline Sementes & 2 & 0 & $\mathrm{Ab}$ & 4 & $\mathrm{Ba}$ & & & \\
Mortas & 2,5 & 0 & $\mathrm{Ab}$ & 5 & $\mathrm{Ba}$ & $1.85^{\mathrm{ns}}$ & $45.71^{*}$ & $2.76^{\mathrm{ns}}$ \\
$(\%)$ & 3 & 0 & $\mathrm{Ab}$ & 8 & $\mathrm{ABa}$ & & & \\
& 3,5 & 0 & $\mathrm{Ab}$ & 18 & $\mathrm{Aa}$ & & \\
\hline
\end{tabular}

${ }^{*}$ significativo para $p<0,05 \mathrm{e}^{\mathrm{ns}}-$ não significativo.

A porcentagem de plântulas anormais foi elevada somente na ausência de saco plástico e quantidade de água igual a 3,5 vezes o peso do substrato, contabilizando-se $77 \%$. Em relação à porcentagem de plântulas anormais contaminadas, houve baixa porcentagem, onde se observou somente plântulas contaminadas na presença de saco plástico, com valores médios de $8,3,7$ e 12\% para a quantidade de água igual $2 ; 2,5 ; 3$ e 3,5 vezes o peso do substrato, respectivamente (Tabela 4 ).

Os tratamentos sem saco plástico apresentaram elevada porcentagem de sementes duras (99 a 100\%), exceto para o tratamento com 3,5 vezes o peso do substrato que exibiu menor porcentagem (23\%). Para a porcentagem de sementes mortas, observou-se que no tratamento com saco plástico e 3,5 vezes o peso do substrato houve alta porcentagem (18\%), enquanto nas condições disponibilidade de água menores (2; 2,5 e 3 vezes o peso do substrato) variou de 4 a $8 \%$.

Esses resultados estão de acordo com o reportado por Silva et al. (2008), os quais trabalharam com a germinação de sementes de Jatropha curcas em diferentes níveis de água inseridos no papel e registraram a redução do número de plântulas normais com o aumento gradativo da quantidade de água utilizada no substrato. Possivelmente, o maior volume de água para o pau-preto $(3,5$ vezes o peso do substrato) causou estresse por saturação hídrica e comprometeu diretamente a germinação e estabelecimento das plântulas.

\section{CONCLUSÃO}

A quantidade de água igual a 2,5 vezes o peso do papel e presença de saco plástico aumenta a velocidade de germinação e propicia maior número de plântulas normais de pau-preto.

Recomenda-se o uso de volume de água igual a 2,5 vezes o peso de papel com a presença de saco plástico em testes de análise de germinação de sementes de pau-preto em laboratório.

\section{REFERÊNCIAS}

AMARO, H.T.R.; DAVID, A.M.S.S.; CONGUSSÚ, L.V.S.; RODRIGUES, B.R.A.; ASSIS, M.O.; VELOSO, C.S. Umedecimento do substrato e temperatura na germinação e vigor de sementes de melão. Semina: Ciências Agrárias, v. 35, n. 3, p. 1119-1130, 2014. http://dx.doi.org/10.5433/1679-0359.2014v35n3p1119

AZERÊDO, G.A.; PAULA, R.C.; VALERI, S.V. Germinação de sementes de Piptadenia moniliformis Benth. sob estresse hídrico. Ciência Florestal, vol. 26, n. 1, p.193-202, 2016. http://dx.doi.org/10.5902/1980509821112

BRASIL. Ministério da Agricultura, Pecuária e Abastecimento. Regras para análise de sementes. Brasília: MAPA; ACS, 2009. 395 p. 
DUARTE, M.M.; KRATZ, D.; CARVALHO, R.L.L.; NOGUEIRA, A.C. Influência do estresse hídrico na germinação de sementes e formação de plântulas de angico branco. Advances in Forestry Science, v. 5, n. 3, p. 375-379, 2018. Disponível em: http://www.periodicoscientificos.ufmt.br/ojs/index.php/afor/article/view/5521/pdf

FLORES, A.V.; ATAÍDE, G.M.; BORGES, E.E.L.; GONÇALVES, L.E.S.; MANFIO, C. $E$. Umedecimento do substrato e temperatura na germinação de sementes de Melanoxylon brauna Schott. Revista Brasileira de Ciências Agrárias, v. 8, n. 3, p. 454-457, 2013. http://dx.doi.org/10.5039/agraria.v8i3a2058

FREITAS, A.D.D.; LEÃO, N.V.M.; REIS, A.R.S.; LINS, A.L.F.A.; FELIPE, S.H.S.; SHIMIZU, E.S.C. Colheita, manejo e características morfológicas e físicas de Aspidosperma spruceanum Benth. Ex Mull.Arg. na Amazônia Oriental. In: SANTOS, S. F.; ARAÚJO-LUCAS, F.C.; MORAES-JUNIOR, M.R.; SANTOS, A.S. (Org.). Bioculturalidade, Conservação e Biotecnologia na Amazônia Oriental. 1 ed. Curitiba-PR: CRV, 2018, v. 01, p. 199-216.

GARCIA, L.C.; MORAES, R.P.; LIMA, R.M.B. Determinação do grau crítico de umidade em sementes de Cenostigma tocantinum Ducke. Revista Brasileira de Sementes, v. 30, n. 3, p. 172-176, 2008. http://dx.doi.org/10.1590/S010131222008000300023

GONÇALVES, E.P.; FRANÇA, P.R.C.; VIANA, J.S.; ALVES, E.U.; GUEDES, R.S.; LIMA, C.R. Umedecimento do substrato e temperatura na germinação de sementes de Parkia platycephala Benth. Ciência Florestal, v. 25, n. 3, p. 563-569, 2015. http://dx.doi.org/10.5902/1980509819607

LEÃO, N.V.M.; FELIPE, S.H.S.; SHIMIZU, E.S.C.; DOS SANTOS FILHO, B.G.; KATO, O.R.; BENCHIMOL, R.L. Biometria e diversidade de temperaturas e substratos para a viabilidade de sementes de ipê amarelo. Informativo ABRATES, v. 25, n. 1, p. 50-54, 2015. Disponível em: https://www.abrates.org.br/img/informations/644f0c7f-9b60-4872-ba9078622c333dd0_IA\%20v25\%20n1.pdf

LEÃO, N.V.M.; SHIMIZU, E.S.C.; FELIPE, S.H.S.; BENCHIMOL, R.L., NASCIMENTO, M.R.S.M. Morfometria, germinação e sanidade de sementes de tachi-peludo. Enciclopédia Biosfera, v. 15, n. 27, p. 142-154, 2018. http://dx.doi.org/10.18677/EnciBio_2018A60

LORENZI, H.; Árvores brasileiras: Manual de identificação e cultivo de plantas arbóreas nativas do Brasil. Instituto Plantarum, Nova Odessa, 2002, 4. ed, v.1, 384 p.

MARCOS-FILHO, J. Fisiologia de Sementes de Plantas Cultivadas. 2. ed. Londrina/PR: ABRATES, 2015, v. 1. 659 p.

MELO, L.D.F.A.; MELO JUNIOR, J.L.A.; ARAUJO NETO, J.C., FERREIRA, V.M., SILVA DAS NEVES, et al.,; Influence of light, temperature and humidity on substrate and osmoconditioning during the germination of Mimosa 
bimucronata (DC) O. Kuntze. Australian Journal of Crop Science, v. 12, n. 07, p. 1177-1183, 2018. http://dx.doi.org/10.21475/ajcs.18.12.07.PNE1139

MELO, R.R.; FERREIRA, A.G.; JUNIOR, F.R. Efeito de diferentes substratos na germinação de sementes de angico (Anadenanthera colubrina (Vell.) Brenan) em condições de laboratório. Revista Científica Eletrônica de Engenharia Florestal, n. $5, \quad$ p. $1-8, \quad 2005 . \quad$ Disponível http://faef.revista.inf.br/imagens_arquivos/arquivos_destaque/MoyLOjNtfPCBmH7_2 013-4-25-14-50-50.pdf

OLIVEIRA JÚNIOR, J.L.; ALMEIDA NETA, M.N.; DAVID, A.M.S.S.; AGUIAR, A.C.M.; GOMES, A.G.O.; AMARO, H.T.R.; DONATO, L.M.S. Substrate moisture and temperature in the germination and vigor of pitaya. Comunicata Scientiae, v. 6, p. 282-290, 2015. https://doi.org/10.14295/cs.v6i3.746

OLIVEIRA-SILVA, D.Y.B. DE; FARIAS, S.G.G. DE; OLIVEIRA, C.V. DE A.; SOUSA, M.B. DE, SILVA, R.B. Umedecimento do substrato na germinação e vigor de sementes de Albizia niopoides Benth. Revista Verde de Agroecologia e Desenvolvimento Sustentável, v. 12, n. 3, p. 397-403, 2017. https://doi.org/10.18378/rvads.v12i3.4500

PEREIRA, M.D.; SILVA ROMEIRO, T.C.O.; FLORES, A.V.; SEVERIANO, R.L. Germinação e biometria de frutos e sementes de Prosopis juliflora (Sw) D.C. Ciência Florestal, v. 28, n. 3, p. 1271-1281, 2018. http://dx.doi.org/10.5902/1980509833379

SANTANA, D.G.; RANAL, M.A. Análise da germinação: um enfoque estatístico. Brasília: Editora Universidade de Brasília, 2004. 248 p.

SANTOS, L.M.D.; FARIAS, S.G.G.D.; SILVA, R.B.; DIAS, B.A.S.; SILVA, L.S.D. Ecophysiology of germination of Parkia platycephala Benth. seeds. Floresta e Ambiente, v. 26, n. 1, p. e20150282, 2019. http://dx.doi.org/10.1590/21798087.028215

SILVA, H.P.; NEVES, J.M.G.; BRANDÃO JÚNIOR, D.S.; COSTA, C.A. Quantidade de água do substrato na germinação e vigor de sementes de pinhão-manso. Revista Caatinga, v. 21, n. 5 (Número Especial), p.178-184, 2008. Disponível em: https://periodicos.ufersa.edu.br/index.php/caatinga/article/view/666/467

SILVA, R.B.; MATOS, V.P.; FARIAS, S.G.G.; SENA, L.H.M.; SILVA, D.Y.B.O. Germinação e vigor de plântulas de Parkia platycephala Benth. em diferentes substratos e temperaturas. Revista Ciência Agronômica, v. 48, p. 142-150, 2017. http://dx.doi.org/10.5935/1806-6690.20170016

SOUSA, F.H.M.; PATRIOTA, J.N.; FERREIRA JÚNIOR, D.F.; OLIVEIRA, L.M.; SOUZA, P.B. Umedecimento do substrato e temperatura na germinação e vigor de sementes de Bixa orellana L. Revista Verde de Agroecologia e Desenvolvimento $\begin{array}{lllllll}\text { Sustentável, } & \text { v. } & 10, & \text { n. } & 2, & \text { p. } & 199-205,\end{array}$ http://dx.doi.org/10.18378/rvads.v10i2.2947

TANAKA, M.A.S.; MARIANO, M.I.A.; LEÃO, N.V.M. Influência da quantidade de água, no substrato sobre a germinação de sementes de amendoim. Revista Brasileira de Sementes, v. 13, n. 1, p. 73-76, 1991. http://dx.doi.org/10.17801/01013122/rbs.v13n1p73-76 